\title{
Identification and Quantification of Aldose Reductase Inhibitory Flavonoids in Herbal Formulation and Extract of Gymnema sylvestre Using HPLC-PDA and LC-MS/MS
}

\author{
Nanjappan Satheeshkumar, Saladi Shantikumar, and Mopuri Komali \\ Department of Pharmaceutical Analysis, National Institute of Pharmaceutical Education and Research (NIPER), \\ Hyderabad, Balanagar, Hyderabad 500037, India \\ Correspondence should be addressed to Nanjappan Satheeshkumar; satish@niperhyd.ac.in
}

Received 11 August 2014; Revised 20 October 2014; Accepted 1 November 2014; Published 26 November 2014

Academic Editor: Branca Silva

Copyright (C) 2014 Nanjappan Satheeshkumar et al. This is an open access article distributed under the Creative Commons Attribution License, which permits unrestricted use, distribution, and reproduction in any medium, provided the original work is properly cited.

Adulteration of herbal supplements is a major issue for many countries. A simple and reliable HPLC-PDA method was developed for quantification of aldose reductase inhibitory flavonoids rutin, quercetin, and kaempferol. The chromatographic separation was performed on a Fortis $\mathrm{C}_{18}$ column in gradient mode with detection at $267 \mathrm{~nm}$. The presence of these markers was confirmed through the accurate $m / z$ values and MS/MS data obtained using quadruple time of flight mass spectrometry (QTOF-MS). The proposed method was successfully applied to examine the amount of these active constituents in antiobese polyherbal formulation and plant extract of Gymnema sylvestre.

\section{Introduction}

Antiobese polyherbal formulation (Ayurslim) is usually used in ayurvedic medicine to treat various obesity-related disorders like diabetes, hypertension, atherosclerosis, gall bladder problems, and certain types of cancer. It comprises five ingredients such as Garcinia cambogia, Gymnema sylvestre, Commiphora wightii, Terminalia chebula, and Trigonella foenum-greacum. These ingredients are present in ayurslim and have considerable effect on weight reduction and lipid profile as it was shown in the report on evaluation of clinical efficacy of ayurslim on body weight, body mass index, lipid profile, and skin fold thickness [1]. Flavonoids occupy a wide space of biologically active compounds that are omnipresent in plants and obtained a lot of significance due to their presence in the human diet, which in turn imparts some favourable effects to promote good health. Aldose reductase is an enzyme which converts the glucose into sorbitol and then fructose. The accumulation of sorbitol in the tissues causes swelling and in turn leads to secondary complications of diabetes like obesity. Earlier studies have revealed that flavonoids such as quercetin $[2,3]$, rutin [4], and kaempferol
[5] were recommended to be responsible for antiobesity activity, followed by inhibiting aldose reductase enzyme [6]. The chemical structures and the proposed fragmentation pattern were shown in Figure 1. In addition to this, flavonoids have exhibited profound pharmacological activities like antiinflammatory, antioxidant, antithrombotic, hepatoprotective, antiviral, and other biological activities [7]. Reports which can be cited with respect to simultaneous estimation of these three components were rather limited. Till now four HPLC reports are available on simultaneous estimation of these flavonoids in the plant extract of sea buckthorn [8], in Melia azedarach Linn. leaves [9], in the leaf extracts of Moringa oleifera Lam. and Raphinus sativus Linn. [10], in Apocynum venetum [11], and in another for Gingko biloba solid oral dosage forms [12]. These methods cannot be applied directly for the estimation in polyherbal formulation and plant extracts because of complexity in the nature and intrinsic variability of chemical constituents. To the best of our knowledge no reports were recorded regarding simultaneous quantitative estimation of three bioactive flavonoids (rutin, quercetin, and kaempferol) in Gymnema sylvestre plant extract and in polyherbal formulation. In recent days, 


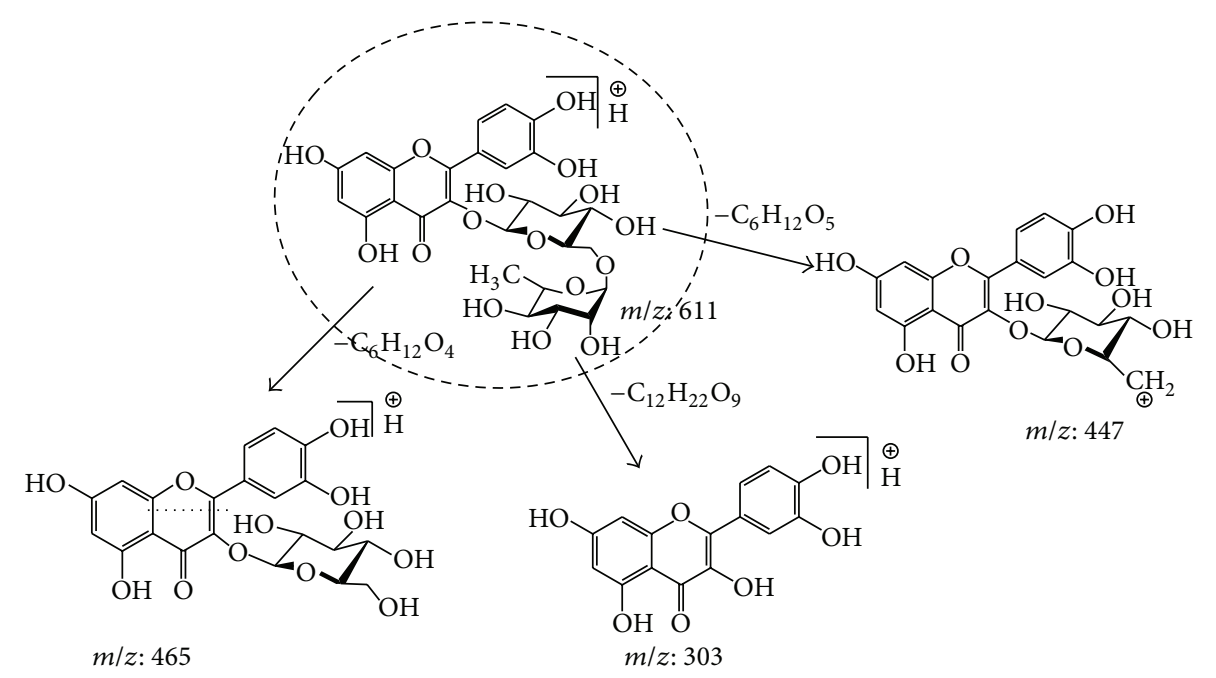

(a)

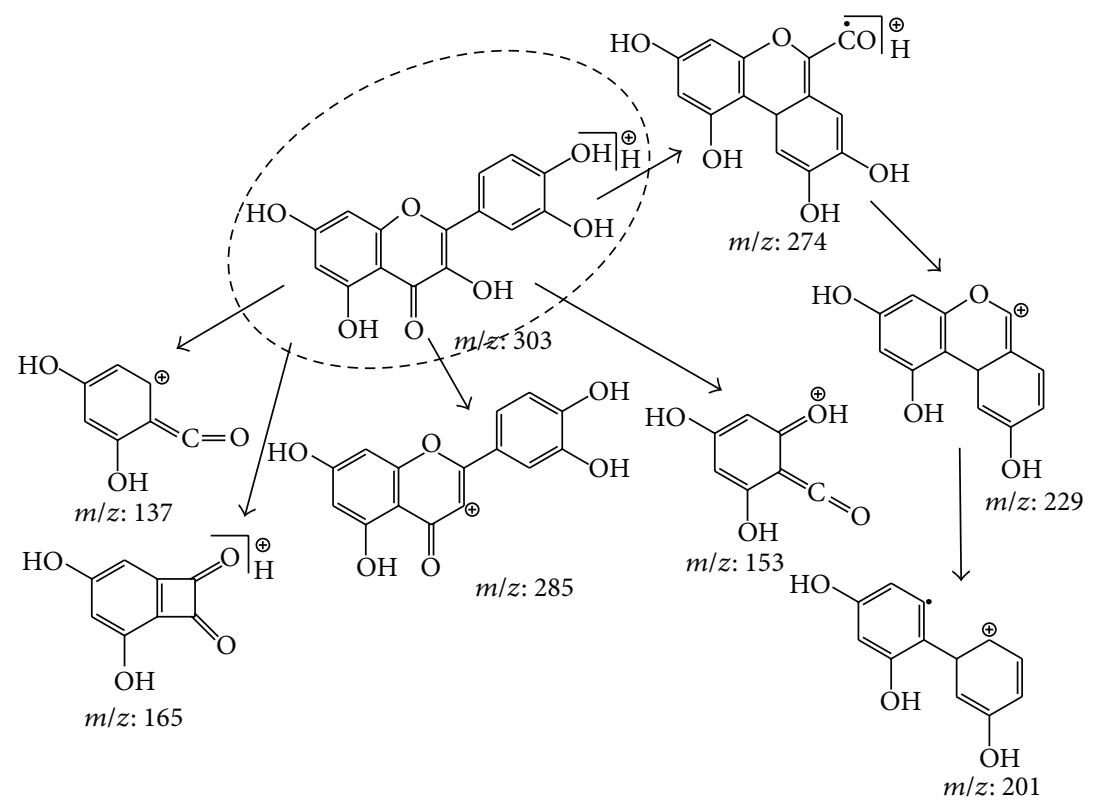

(b)

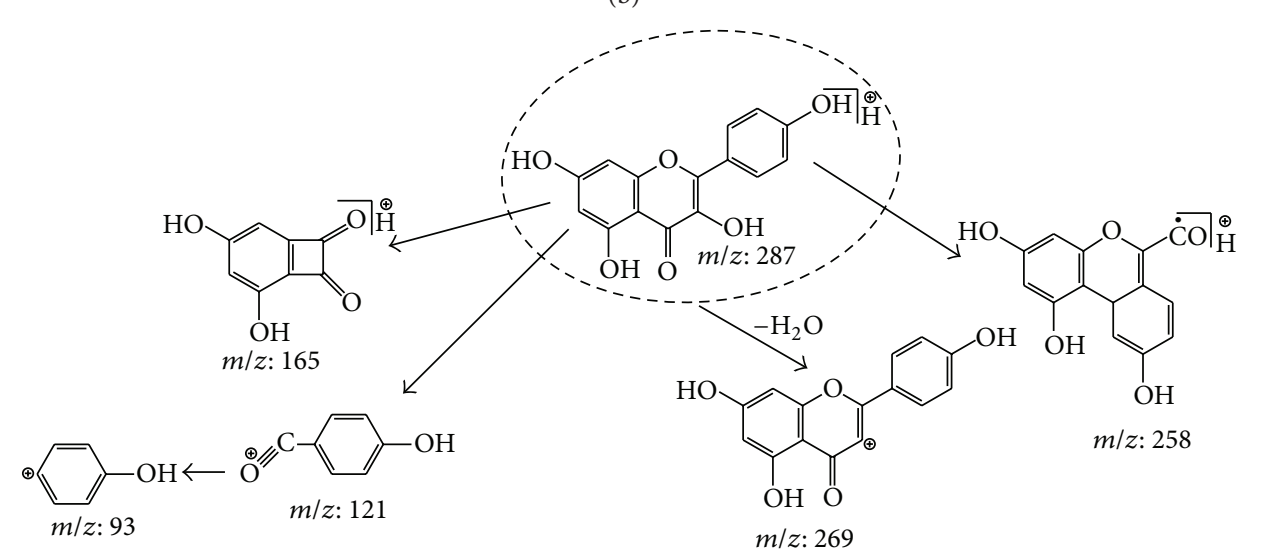

(c)

FIGURE 1: Structures of rutin (a), quercetin (b), and kaempferol (c). Proposed scheme of the fragmentation pattern was also elucidated. 
plant based medicines are gaining more attention globally due to their long term existence in clinical practice and minimal side effects compared with synthetic drugs and are offering a broad spectrum of activity since ancient times. But Indian herbal drugs still have low acceptability in the world market due to inadequate quality standards. In order to overcome these barriers, there is a need to develop good quality standards. Estimation of phytoactive principles in herbal medicines by applying modern analytical tools is essential for establishing authenticity and reliability of prescription and usage of herbal drugs. The welldeveloped quality standards can be achieved only through systemic evaluation of plant material using modern analytical techniques including chromatographic techniques. Recently the concept of marker based standardisation was attaining more significance; identification of major and unique compounds in herbs as markers and development of analytical methodologies for monitoring them are two essential steps involved in marker based standardisation [13]. Among all the chromatographic techniques used, HPLC coupled with DAD detector has emerged as a simple, reliable, and efficient method for simultaneous quantitative analysis of two or more constituents. The current research aimed to develop an accurate, simple, reliable, sensitive, and less time-consuming HPLC method for simultaneous quantitative estimation of quercetin, kaempferol, and rutin in polyherbal formulation as well as in plant extract (Gymnema sylvestre). The developed method was validated as per ICH guidelines. It can be applied as a quality control tool for standardisation of commercially available antiobese polyherbal formulation and also for the maintenance of batch to batch consistency of formulation.

\section{Materials and Methods}

2.1. Materials. HPLC grade methanol was procured from E. Merck, Mumbai, India. Ammonium acetate crystals used for buffer preparation were obtained from RFCL limited, Haryana. Glacial acetic acid, used for adjusting buffer $\mathrm{pH}$, was acquired from S D Fine-Chem Limited, Mumbai. Reference standards of quercetin, kaempferol, and rutin were purchased from Sigma Aldrich Chemicals, India. Plant extracts were procured from Herbo Chem Pharma limited, Hyderabad. Ayurslim capsule was procured from the local market.

2.2. Chromatographic Conditions for HPLC. HPLC was performed on a Waters 2695 alliance system assembled with a quaternary solvent delivery system, an online degasser, an autosampler, and a 2996 photodiode array detector, which was used for chromatographic analysis. All separations were achieved on a Fortis $C_{18}$ column $(150 \times 4.6 \mathrm{~mm}, 5 \mu \mathrm{m})$ by using Empower software. The mobile phase used was $10 \mathrm{mM}$ ammonium acetate buffer of $\mathrm{pH} 4.0$ (solvent $\mathrm{A}$ ) and methanol (solvent B). Mobile phase was degassed and filtered through $0.25 \mu \mathrm{m}$ filter prior to use.

2.3. LC-MS/MS. LC-MS and LC-MS/MS experiments were performed on an Agilent 6540 Ultra High Definition (UHD) Accurate-Mass Q-TOF LC/MS system (Agilent Technologies,
USA). The LC of the instrument was an Agilent 1200 infinity series with an integrated quaternary pump, a vacuum degasser, autoinjector, and column oven. The system also contained a PDA detector. All MS acquisitions were performed in the positive atmospheric pressure ionisation mode. The capillary voltage and cone voltage were $4 \mathrm{kV}$ and $35 \mathrm{~V}$, respectively. The collision energy was $20 \mathrm{eV}$. The instrument was operated at a resolution of 10,000. Mass hunter software was used for data acquisition and evaluation.

2.4. Preparation of Standard Stock Solution. Standard stock solutions were prepared separately by dissolving $10 \mathrm{mg}$ of each compound in $10 \mathrm{~mL}$ of methanol to get concentration of $1000 \mu \mathrm{g} \mathrm{mL}^{-1}$. For calibration curve, aliquots of 60 to $140 \mu \mathrm{g} \mathrm{mL}^{-1}, 35$ to $85 \mu \mathrm{g} \mathrm{mL}^{-1}$, and 30 to $70 \mu \mathrm{g} \mathrm{mL}^{-1}$ were prepared from the above stocks for rutin, quercetin, and kaempferol, respectively.

2.5. Preparation of Sample Solution. About $300 \mathrm{mg}$ of dried leaf powder of Gymnema sylvestre was weighed and dissolved in $30 \mathrm{~mL}$ of methanol, sonicated for $30 \mathrm{~min}$. After sonication, the extract was cooled down to ambient temperature. Then the extract was filtered by passing through $0.4 \mu \mathrm{m}$ syringe filter, and $0.1 \mathrm{~mL}$ of the filtrate is finally diluted with $10 \mathrm{~mL}$ of methanol. This diluted solution was transferred to HPLC vial for analysis. About $400 \mathrm{mg}$ of capsule powder was weighed and dissolved in $40 \mathrm{~mL}$ of methanol, sonicated for $30 \mathrm{~min}$. After cooling, the sonicated extract was filtered by passing through $0.4 \mu \mathrm{m}$ syringe filter, and from that $0.1 \mathrm{~mL}$ was taken and diluted to $10 \mathrm{~mL}$ of methanol. This solution was transferred to HPLC vial prior to analysis.

\section{Method Validation}

Method validation parameters such as system suitability, linearity, LOD, LOQ, precision, accuracy, and robustness were carried out as per International Conference on Harmonization (ICH) guidelines [14].

3.1. Linearity. Linearity was measured by calibration curves which were generated by three repeated injections of standard solutions at five concentration levels. Linearity was demonstrated by using a plot of peak area with corresponding concentration. Results were expressed as the values of correlation coefficient $\left(r^{2}\right)$.

3.2. Precision. The precision of system was carried out by six replicate injections from the same vial of standard at $100 \%$ analytical concentration and was expressed in terms of \%RSD. Method precision was determined by six different samples of standard analysed at $100 \%$ analytical concentration and then \%RSD was calculated (acceptance criteria: \%RSD should not be greater than $2.0 \%$ ).

3.3. Accuracy. Recovery test was carried out for the evaluation of accuracy. Three different concentrations (80\%, 100\%, and $120 \%$ ) of mixture of three marker compounds were added 
to known amount $(100 \mu \mathrm{g} / \mathrm{mL})$ of the formulation sample and analysed at three replicates. Percentage recovery was calculated.

3.4. $L O D$ and $L O Q$. LOD and LOQ represent the sensitivity of method which indicates that the method is capable of detecting and quantifying trace amount of three compounds. It is a measure of $S / N$ ratio and expressed as the values of $3: 1$ and $10: 1$ for LOD and LOQ, respectively.

3.5. Robustness. Robustness was determined by making slight changes in method parameters like flow rate, buffer strength, $\mathrm{pH}$, and temperature. The effect of these changes on resolution, retention time, area, and USP resolution was observed. Results were expressed in terms of $\%$ mean difference. Values within the difference of $\pm 5 \%$ were accepted.

3.6. Stability. Stability was carried out by subjecting mixture of standard solutions to room temperature for $24 \mathrm{hrs}$ and by storing the solutions in refrigerator at $2-8^{\circ} \mathrm{C}$ for $24 \mathrm{hrs}$. Then results were compared with freshly prepared standard solutions. No considerable changes were observed in peak area, peak shape, and retention time.

\section{Results and Discussion}

4.1. Optimization of Sample Preparation. Sample extraction marks a crucial step in natural product analysis. The importance of sample preparation in analytical methods was best reviewed by Satheeshkumar et al. [15]. It is influenced by chemical nature of biomarker, extraction method employed, particle size of sample, and presence of interfering substances. Commonly used extraction solvents for flavonoids are alcohols (methanol, ethanol), acetone, diethyl ether, and ethyl acetate. In the present study, methanol was employed as a suitable extraction solvent considering the solubility of compounds. In similar lines, ultrasonication was employed as an extraction method as it showed good recovery with acceptable resolution in comparison with refluxing and centrifugation. The optimised sample extraction procedure was ultrasonication for $30 \mathrm{~min}$ using methanol as an extraction solvent.

4.2. Development of HPLC Method. Chromatographic separation of rutin, quercetin, and kaempferol is challenging as they are structurally similar. These components were often found to be attached to sugars (rutin) and aglycones (quercetin and kaempferol). Method development was initially done using various columns and mobile phases. The best separation was achieved on Fortis $\mathrm{C}_{18}$ column using gradient elution of $10 \mathrm{mM}$ ammonium acetate buffer of $\mathrm{pH}$ (4.0) (eluent-A) and methanol (eluent-B). Run time of $10 \mathrm{~min}$ with a gradient elution: $0.0-1.5 \mathrm{~min}(35 \% \mathrm{~B})$, $1.5-6.5 \mathrm{~min}(35-85 \% \mathrm{~B}), 6.5-8.0 \mathrm{~min}(85-35 \% \mathrm{~B})$, and $8.0-$ $10.0 \mathrm{~min}(35 \% \mathrm{~B})$ was used. The detection was carried out at a wavelength of $267 \mathrm{~nm}$ with a flow rate of $1 \mathrm{~mL} / \mathrm{min}$. The retention times of rutin, quercetin, and kaempferol were 5.29, 5.97, and $6.34 \mathrm{~min}$, respectively. The presence of three

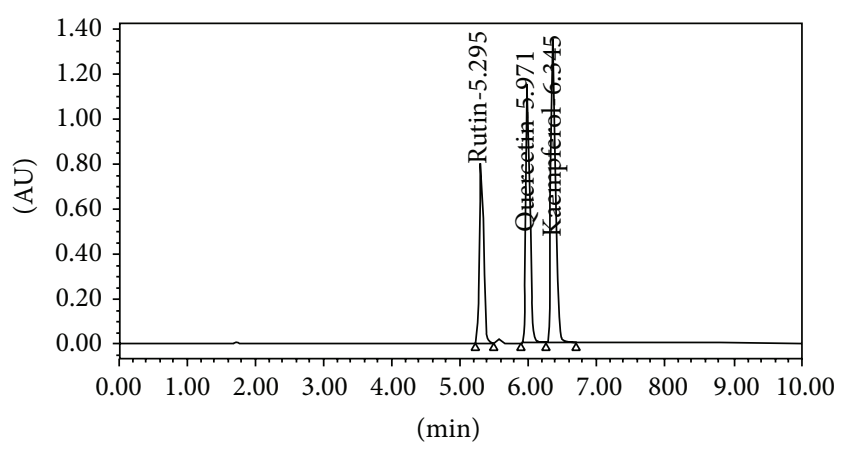

FIGURE 2: A typical chromatogram of standard sample wherein neat separation of all active constituents was depicted.

markers in herbal formulation was confirmed by comparing the retention times and UV spectra with their respective standards. A representative chromatogram of the separation was shown in Figure 2.

4.3. LC-ESI/QTOF Analysis. As the developed method is mass spectrometry (MS) compatible, the presence of markers in polyherbal formulation and plant extracts was further confirmed using LC-MS/MS analysis. The representative total ion chromatograms of standards, plant extract, and polyherbal formulation are shown in Figure 3. The mass spectra have confirmed the presence of rutin, quercetin, and kaempferol by their parent ion $m / z$ value of 610,303 , and 287 in both polyherbal formulation and plant extract. The overview of the fragmentation pattern of all the three flavonoids was discussed in Figure 1.

4.4. MS/MS of Rutin. Elucidation of the structures of fragments of rutin was carried out by careful examination of ESI-MS/MS spectrum (Figure 4) of its $[\mathrm{M}+\mathrm{H}]^{+}$ion $(\mathrm{m} / z$ 610). The spectrum showed abundant ions at $m / z 465$ (loss of $\mathrm{C}_{6} \mathrm{H}_{12} \mathrm{O}_{4}$ ), $m / z 447$ (loss of $\mathrm{C}_{6} \mathrm{H}_{12} \mathrm{O}_{5}$ ), and $m / z 303$ (loss of $\mathrm{C}_{12} \mathrm{H}_{22} \mathrm{O}_{9}$ ). It can be observed that rutin upon loss of rutinose moiety gets converted to quercetin.

4.5. MS/MS of Quercetin. The ESI-MS/MS spectrum of quercetin was depicted in Figure 4 . The spectrum showed abundant ions at $\mathrm{m} / \mathrm{z} 285$ (loss of $\mathrm{H}_{2} \mathrm{O}$ ), $\mathrm{m} / \mathrm{z} 274$ (loss of $\mathrm{CHO}$ ), $m / z 165$ (loss of $\mathrm{C}_{7} \mathrm{H}_{6} \mathrm{O}_{3}$ ), $\mathrm{m} / z 137$ (loss of $\mathrm{C}_{8} \mathrm{H}_{5} \mathrm{O}_{4}$ ), $\mathrm{m} / z 153$ (loss of $\mathrm{C}_{8} \mathrm{H}_{5} \mathrm{O}_{3}$ ), $\mathrm{m} / z 229$ (loss of $\mathrm{C}_{2} \mathrm{HO}_{3}$ ), and $\mathrm{m} / \mathrm{z}$ $201\left(\mathrm{C}_{3} \mathrm{HO}_{4}\right)$.

4.6. MS/MS of Kaempferol. The ESI-MS/MS spectrum of kaempferol was depicted in (Figure 4). The spectrum showed abundant ions at $m / z 269$ (loss of $\mathrm{H}_{2} \mathrm{O}$ ), $\mathrm{m} / z 258$ (loss of $\mathrm{CHO}$ ), $\mathrm{m} / \mathrm{z} 165$ (loss of $\mathrm{C}_{7} \mathrm{H}_{5} \mathrm{O}_{2}$ ) and $\mathrm{m} / \mathrm{z} 121$ (loss of $\mathrm{C}_{8} \mathrm{H}_{5} \mathrm{O}_{4}$ ).

\subsection{Method Validation}

4.7.1. Linearity. This method was found to be linear from $60-140 \mu \mathrm{g} \mathrm{mL}^{-1}$ for rutin, $35-85 \mu \mathrm{g} \mathrm{mL}^{-1}$ for quercetin, and 


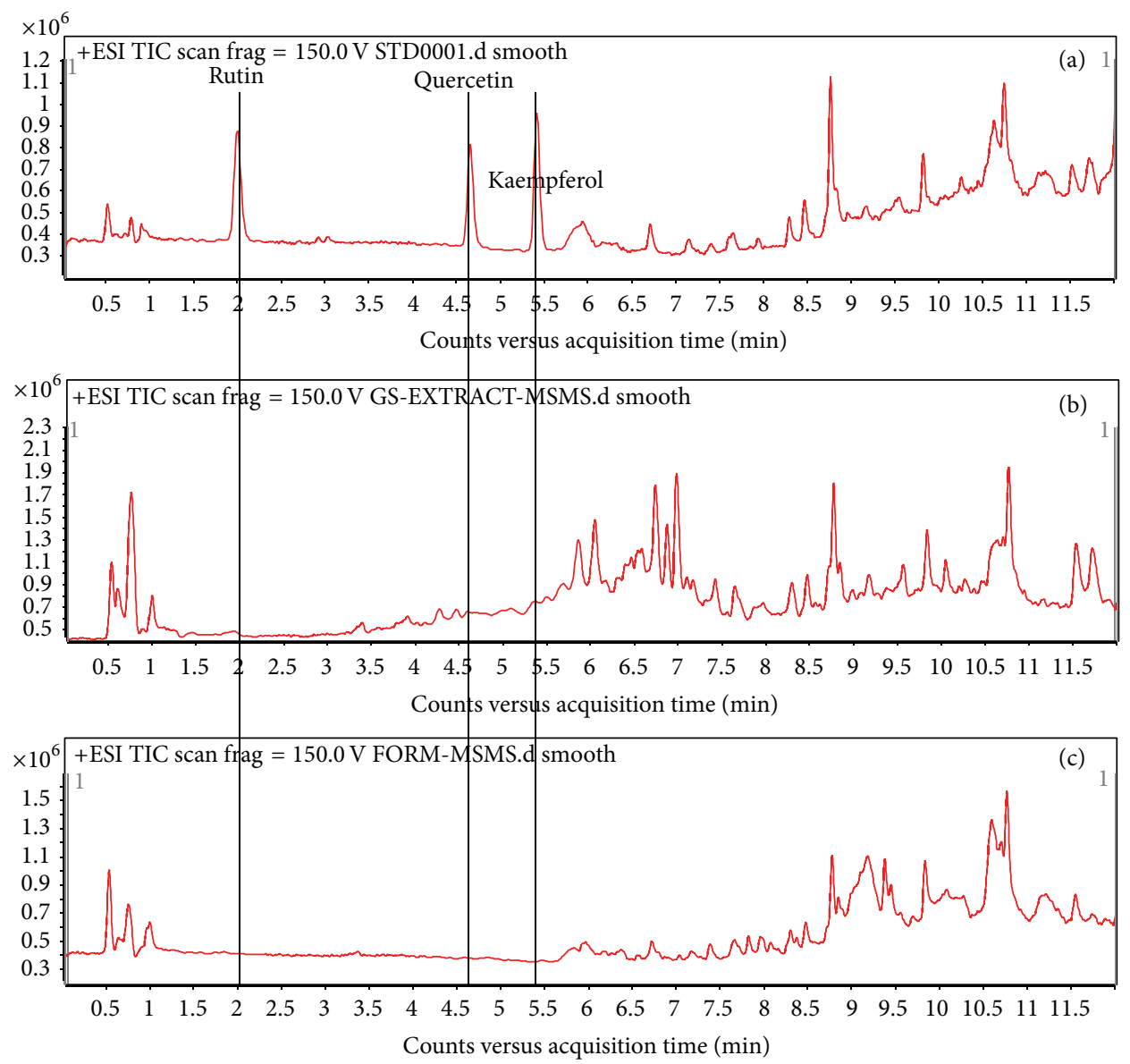

Figure 3: Total ion chromatogram of (a) (standard sample), (b) (plant extract), and (c) (herbal formulation).

30-70 $\mu \mathrm{g} \mathrm{mL}^{-1}$ for kaempferol. The correlation coefficient was found to be $\geq 0.99$ for all three components. The regression line analysis data was summarized in Table 1.

4.7.2. Precision and Accuracy. System precision and method precision of the HPLC method were investigated using replicate injections $(n=3)$ of all the three standards. For accuracy, recovery values of all the three components were within acceptable limits. The developed method was found to be precise and accurate. The results were shown in Table 2 .

4.7.3. LOD and LOQ. LOD and LOQ were estimated based on signal to noise ratio. LOD and LOQ of three marker compounds were within the range of 0.006 to $0.01 \mu \mathrm{g} \mathrm{mL}^{-1}$ and 0.02 to $0.03 \mu \mathrm{g} \mathrm{mL}^{-1}$, respectively, and these values were summarized in Table 3.

4.7.4. Robustness. For robustness study, parameters like flow rate, buffer strength, $\mathrm{pH}$ of buffer, and temperature were studied. The method was not much effected with regard to resolution and peak tailing. Therefore, the proposed method is robust and the results were shown in Table 4.
4.7.5. Quantification of Markers in Polyherbal Formulation. The percentage assay value for samples in polyherbal formulation was found to be $0.029 \%, 0.012 \%$, and $0.003 \%$ for rutin, quercetin, and kaempferol, respectively, while the extract of Gymnema sylvestre was found to be $0.067 \%, 0.081 \%$, and $0.038 \%$ for rutin, quercetin, and kaempferol, respectively. The present method resolved all three standards in the presence of other phytochemicals in Gymnema sylvestre which indicates that the method is specific. This validated method was suitable for qualitative and quantitative analysis of rutin, quercetin, and kaempferol in the methanolic extract of Gymnema sylvestre as well as in polyherbal formulation.

\section{Conclusion}

The analysis and quality control of herbal medicine are progressing in the direction of extensive and comprehensive way of research, in order to disclose the facts behind inherent complex nature of herbal drugs and preparations. This inventive research attempt has been made to outline the applicability of chromatographic techniques on quality, safety, and efficacy of herbal medicines. The established method was rapid, simple, and reliable for simultaneous quantitative estimation of these three bioactive flavonoids (rutin, quercetin, and kaempferol) in plant extract as well 


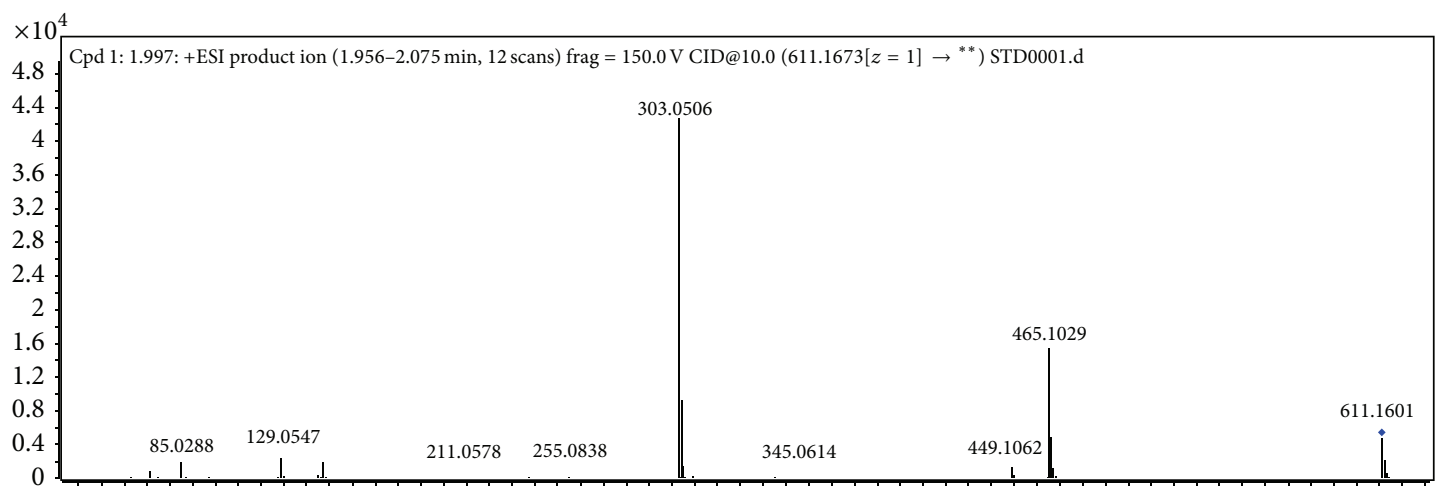

406080100120140160180200220240260280300320340360380400420440460480500520540560580600620 Counts versus mass-to-charge $(\mathrm{m} / \mathrm{z})$

(a)

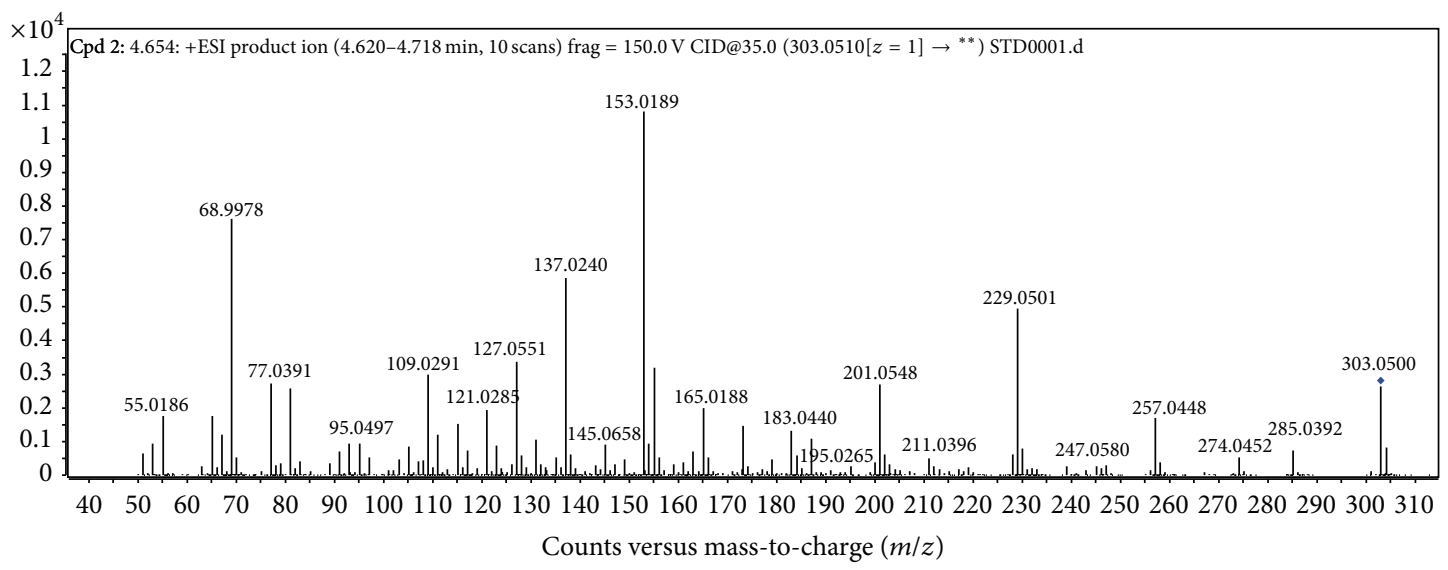

(b)

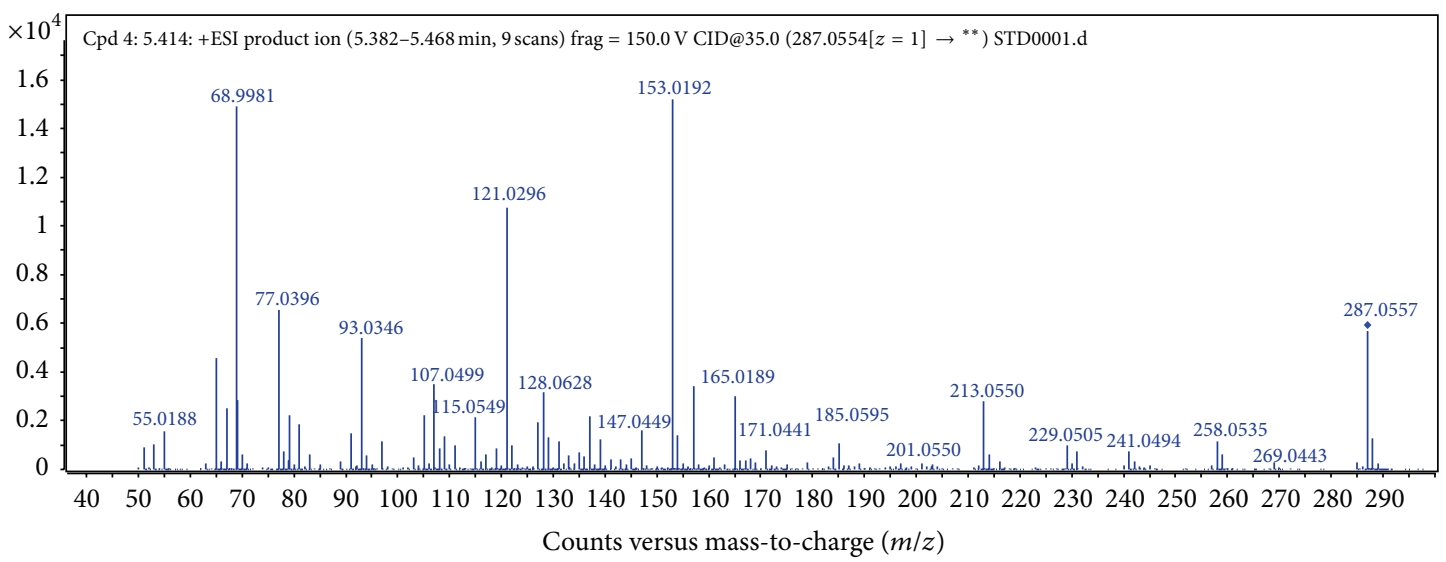

(c)

FIGURE 4: LC-MS/MS spectra’s of rutin (a), quercetin (b), and kaempferol (c).

TABLE 1: Linearity and regression data.

\begin{tabular}{lcccc}
\hline Compounds & Retention time $(\mathrm{min})$ & Regression equation & $r^{2}$ & $\begin{array}{c}\text { Linearity range } \\
(\mu \mathrm{g} / \mathrm{mL})\end{array}$ \\
\hline Rutin & 5.29 & $y=29028 x+45324$ & 0.992 & $60-140$ \\
Quercetin & 5.97 & $y=53046 x+18553$ & 0.997 & $35-85$ \\
Kaempferol & 6.34 & $y=63663 x+17561$ & 0.995 & $30-70$ \\
\hline
\end{tabular}


TABLE 2: Results of precision and accuracy.

\begin{tabular}{lccc}
\hline Parameters & Rutin & Quercetin & Kaempferol \\
\hline Precision (\%RSD) & & & \\
System precision & 0.8 & 0.77 & 0.66 \\
Method precision & 0.55 & 0.55 & 0.55 \\
Accuracy (percentage recovery) & $99.07-104.3$ & $98.03-105.3$ & $101.03-104.3$ \\
\hline
\end{tabular}

TABLE 3: Respective values of LOD and LOQ for all three flavonoids.

\begin{tabular}{lccc}
\hline Parameters & Rutin & Quercetin & Kaempferol \\
\hline LOD $(\mu \mathrm{g} / \mathrm{mL})$ & 0.01 & 0.0066 & 0.0066 \\
LOQ $(\mu \mathrm{g} / \mathrm{mL})$ & 0.03 & 0.02 & 0.02 \\
\hline
\end{tabular}

TABLE 4: Results of robustness study.

\begin{tabular}{|c|c|c|c|c|c|}
\hline \multirow{2}{*}{ Parameters } & \multirow{2}{*}{ Tested levels } & \multirow{2}{*}{$\begin{array}{l}\text { Resolution between quercetin } \\
\text { and kaempferol }\end{array}$} & \multicolumn{3}{|c|}{ Tailing factor } \\
\hline & & & Rutin & Quercetin & Kaempferol \\
\hline \multirow{2}{*}{ Column temperature $\left({ }^{\circ} \mathrm{C}\right)$} & 35 & 3.27 & 1.44 & 1.43 & 1.45 \\
\hline & 45 & 3.57 & 1.22 & 1.43 & 1.43 \\
\hline \multirow{2}{*}{ Flow rate $(\mathrm{mL} / \mathrm{min})$} & 0.9 & 3.51 & 1.36 & 1.43 & 1.46 \\
\hline & 1.1 & 3.48 & 1.28 & 1.47 & 1.44 \\
\hline \multirow{2}{*}{ Buffer concentration (mM) } & 5 & 3.48 & 1.35 & 1.43 & 1.47 \\
\hline & 15 & 3.43 & 1.34 & 1.43 & 1.48 \\
\hline \multirow{2}{*}{$\mathrm{pH}$ of buffer } & 4.2 & 3.34 & 1.35 & 1.45 & 1.49 \\
\hline & 3.8 & 3.30 & 1.37 & 1.49 & 1.42 \\
\hline
\end{tabular}

as in polyherbal formulation. This study would assist in standardizing the extracts and polyherbal formulation which are further helpful in forecasting and regulating the quality of herbal drugs and commercial herbal preparations.

\section{Conflict of Interests}

The authors declare no conflict of interests.

\section{Acknowledgments}

Nanjappan Satheeshkumar is thankful to the Science and Engineering Research Board (SERB), DST, New Delhi, India, for providing Start-Up Research Grant (Young Scientists) (no. SB/YS/LS-82/2013). The authors would also like to thank Dr. Ahmed Kamal, Project Director, NIPER Hyderabad, for his kind support.

\section{References}

[1] A. K. Singh, P. S. Patki, and S. Mitra, "Evaluation of clinical efficacy of ayurslim on body weight, body mass index, lipid profile and skin fold thickness: a phase IV clinical trial," The Antiseptic, vol. 105, pp. 241-243, 2008.

[2] R. L. Edwards, T. Lyon, S. E. Litwin, A. Rabovsky, J. D. Symons, and T. Jalili, "Quercetin reduces blood pressure in hypertensive subjects," Journal of Nutrition, vol. 137, no. 11, pp. 2405-2411, 2007.
[3] Y. Yamamoto and E. Oue, "Antihypertensive effect of quercetin in rats fed with a high-fat high-sucrose diet," Bioscience, Biotechnology and Biochemistry, vol. 70, no. 4, pp. 933-939, 2006.

[4] A. Ziaee, F. Zamansoltani, M. Nassiri-Asl, and E. Abbasi, "Effects of rutin on lipid profile in hypercholesterolaemic rats," Basic and Clinical Pharmacology and Toxicology, vol. 104, no. 3, pp. 253-258, 2009.

[5] S. F. Yu, C. T. Shun, T. M. Chen, and Y. H. Chen, “3-O- $\beta-D-$ Gucosyl- $(1 \rightarrow 6)-\beta$-D-glucosyl-kaempferol isolated from Sauropus androgenus reduces body weight gain in Wistar rats," Biological and Pharmaceutical Bulletin, vol. 29, no. 12, pp. 25102513, 2006.

[6] G. B. Reddy, P. Muthenna, C. Akileshwari, M. Saraswat, and J. M. Petrash, "Inhibition of aldose reductase and sorbitol accumulation by dietary rutin," Current Science, vol. 101, no. 9, pp. 1191-1197, 2011.

[7] B. H. Havsteen, "The biochemistry and medical significance of the flavonoids," Pharmacology and Therapeutics, vol. 96, no. 2-3, pp. 67-202, 2002.

[8] Y. Zu, C. Li, Y. Fu, and C. Zhao, "Simultaneous determination of catechin, rutin, quercetin kaempferol and isorhamnetin in the extract of sea buckthorn (Hippophae rhamnoides L.) leaves by RP-HPLC with DAD," Journal of Pharmaceutical and Biomedical Analysis, vol. 41, no. 3, pp. 714-719, 2006.

[9] A. S. R. Mohammed Fazil Ahmed, "Simultaneous determination of phenolic compounds in Melia Azedarach. Linn leaves by high-performance liquid chromatography," Indian Journal of Applied Research, vol. 3, pp. 429-431, 2013.

[10] V. C. Devaraj, B. G. Krishna, and G. L. Viswanatha, "Simultaneous determination of quercetin, rutin and kaempferol in the leaf 
extracts of Moringa oleifera Lam. and raphinus sativus Linn, by liquid chromatography-tandem mass spectrometry," Journal of Chinese Integrative Medicine, vol. 9, no. 9, pp. 1022-1030, 2011.

[11] Q. Zhang, L. Wu, A. Yan, F. Hu, Y. Yuan, and J. Wang, "Simultaneous determination of six flavonoids in Apocynum venetum by HPLC," Zhongguo Zhongyao Zazhi, vol. 36, no. 5, pp. 589-593, 2011.

[12] M.-J. Dubber and I. Kanfer, "High-performance liquid chromatographic determination of selected flavonols in Ginkgo biloba solid oral dosage forms," Journal of Pharmacy and Pharmaceutical Sciences, vol. 7, no. 3, pp. 303-309, 2004.

[13] M. K. Gharate and V. S. Kasture, "Development and validation of RP-HPLC method for determination of marker in polyherbal marketed Kankasava formulations," Der Pharmacia Lettre, vol. 3, no. 5, pp. 28-33, 2011.

[14] "Validation of analytical procedures: test and methodology", in Proceedings of the International Conference on Harmonization (ICH '05), Guidelines Q2 (R1), Geneva, Switzerland, 2005, http://www.ich.org/.

[15] N. Satheeshkumar, S. Shantikumar, and R. Srinivas, "Pioglitazone: a review of analytical methods," Journal of Pharmaceutical Analysis, vol. 4, no. 5, pp. 295-302, 2014. 

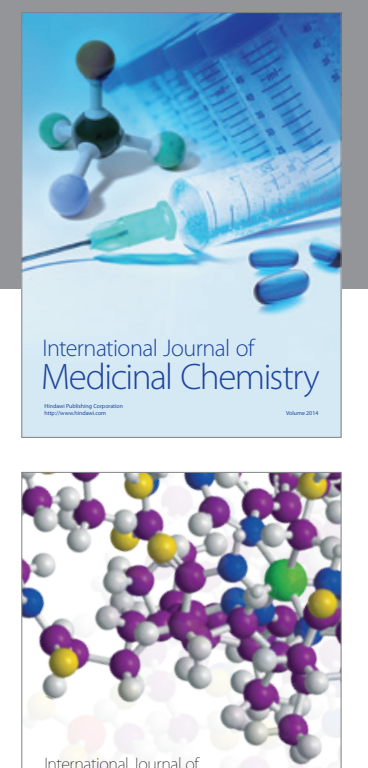

\section{Carbohydrate} Chemistry

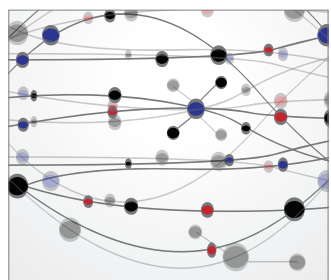

The Scientific World Journal
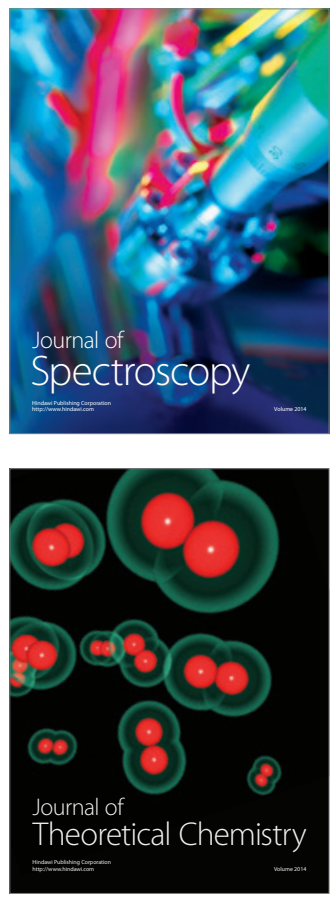
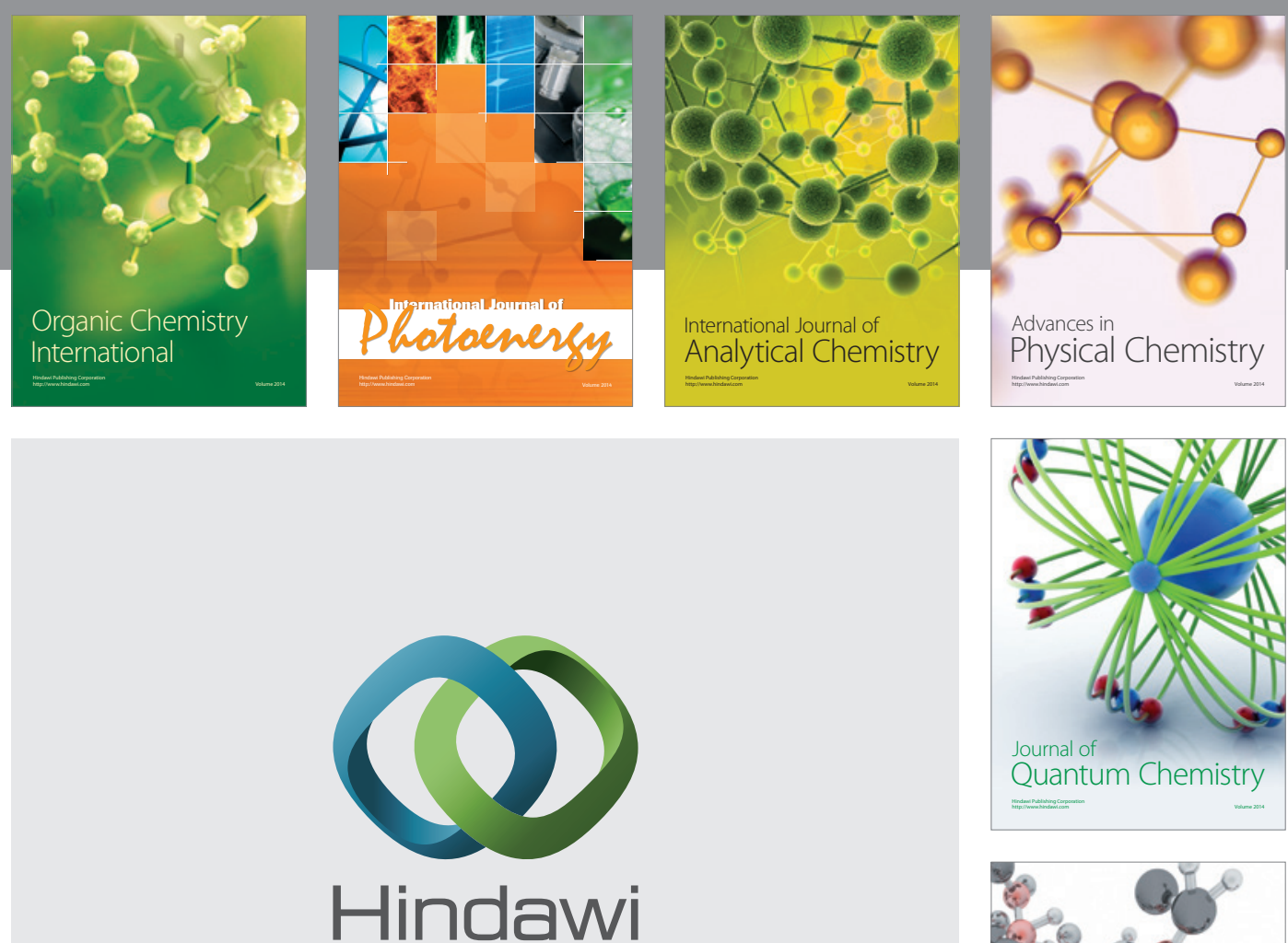

Submit your manuscripts at

http://www.hindawi.com

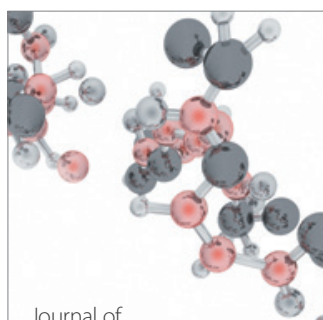

Analytical Methods

in Chemistry

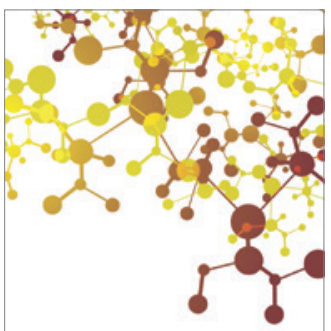

Journal of

Applied Chemistry

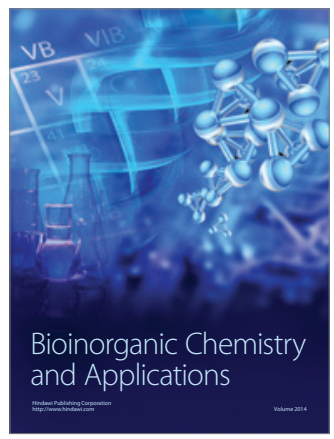

Inorganic Chemistry
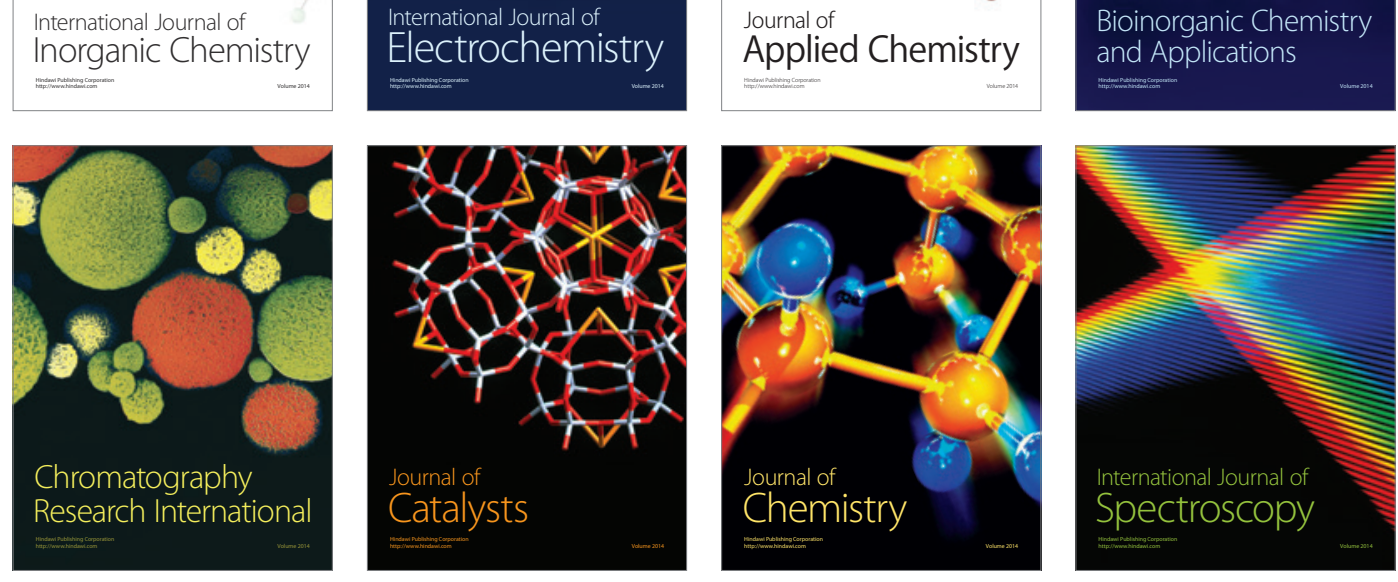